\title{
Research on the Tripartite Cooperation of the Venture Capital Institutions, Business Incubators and Start-Ups and Ethical Risk from the Perspective of Game Theory
}

\author{
lin Liu \\ Wuhan University of Technology \\ Wuhan, China \\ 18120447010@163.com
}

\begin{abstract}
From the perspective of the game theory, this paper analyzes the relationship among the venture capital institutions, business incubators and start-ups. The author establishes a tripartite game model, obtains the game equilibrium solution and puts forward optimal choice behavior for three parties. Due to the information asymmetry, it will generate the problem about ethical risk in tripartite cooperation. This paper analyzes this problem and its cause. Meanwhile, the author puts forward corresponding countermeasures and suggestions to solve out this problem, which can promote the grown of start-ups, keep the business incubators running smoothly and make the venture capital institutions maximize their benefits.
\end{abstract}

Keywords—game theory; business incubator; venture capital ethical risk

\section{INTRODUCTION}

In June 1987, the first business incubator was established in Wuhan. And the incubator in China has been developing vigorously for 30 years ago. The operation main body is also led by the government, to the local government and large enterprises, to the venture capital institutions or various kinds of private capital founded together.

In this context, the tripartite cooperation among venture capital institutions, business incubators and start-ups has become more common and important. On the one hand, business incubators and start-ups face the problem of shortage of funds in the development process. On the other hand, venture capital institutions hold much idle money, but they can't find ideal investee because of asymmetric information or unwillingness to bear high search costs.

Venture capital institutions choose the start-ups that have great potential in incubators as investee, which not only solve the problem of capital shortage for start-ups, but also make venture capital institutions to reduce the risk of investment. Business incubators provide a platform for start-ups. If startups can enter business incubators, they can get funds from venture capital institutions, value-added services and consulting services provided by business incubators. Then, their survival rate and success rate will also be greatly enhanced. Incubators, as a platform, establish a two-way interaction about information flow and capital flow between venture capital institutions and start-ups.it also achieve the effective allocation of resources.

Through cooperation, the three parties can seize the market opportunities more rapidly and effectively, transform market information, capital and management into competitive advantages and form revenue. However, due to the asymmetric information, the three parties face the problem of ethical risk. Therefore, on the basis of predecessor studies, this paper uses game theory to study the tripartite cooperation and ethical risk of the three-parties. This paper also provides references for improving the development of business incubators, broadening business vision of venture capital institutions and promoting start-ups develop rapidly.

\section{THE SUMmARY OF THE RESEARCH ON THE FINANCING OF COOPERATION MODE}

Up to now, domestic scholars conduct a great deal of researches about the cooperation modes. According to the situation of technology business incubators participated in project investment, Liming Zhao [1] divides cooperation modes into two types: internal cooperation and external cooperation .He proposes that external cooperation mode has efficient, flexible and secure advantages.

Yan Hu and Yun Chen [2] discussed six possible modes of business incubator and venture capital from the perspectives of complementary functions, investment methods and company formation:(1)business incubators attract venture capital institutions at preferential prices.(2)Incubators establish investment company and do investors.(3)business incubators and venture capital institutions conduct equity cooperation and manage incubators jointly.(4) business incubators and venture capital institutions fund the new investment agency together.(5) business incubators and other enterprises fund venture capital institutions.(6) Investment institutions establish the incubators to select good projects.

Kun Zhao and Rui Sun [3] divide the integration modes of $\mathrm{S} \& \mathrm{~T}$ incubators and venture capital venture capital institutions into two types: direct integration and indirect integration. Direct integration models include joint-stock 
model, union mode and contract mode. Indirect integration modes include middle institutional mode and the two sides set up a new business jointly mode.

In order to simplify the tripartite game problems, this article doesn't consider the situation of direct investment in incubators, but analyzes that the business incubators provide services for start-ups and venture capital institutions invest in start-ups.

\section{TRIPARTITE GAME MODEL}

\section{A. Model Specification}

In the process of tripartite cooperation, whether the startups can be incubated successfully and the overall value after start-ups grown are related to funds invested by the venture capital institutions (I), the effort level of the start-ups themselves (De) and business incubators service level for startups (Ds) .If either party has any problem, it will lead to the failure. We define the three probabilities of incubating success among the three parties as X (I), Y (De), Z (Ds). X, Y, Z are the respectively increasing functions of $I$, De, Ds, and their marginal benefits are decreasing, $0 \leq X(I), Y\left(D_{e}\right), Z\left(D_{S}\right) \leq 1$.

After the success of start-ups, the benefits obtained are R, R as a function of I, De and Ds. We assume that the three parties obtain the income in the final stage. The capital, service and effort invested by the three-parties are indispensable for the start-ups. If one party can't be provided, the entrepreneurial activity will fail: $R\left(0, D_{e}, D_{S}\right)=R\left(I, 0, D_{S}\right)=R\left(I, D_{e}, D_{S}\right)=0$.

The effort level of start-ups and the level service provided by incubators can't be observed by outside. We define that the cost of efforts and business incubators services respectively as $\mathrm{C}$ (De), C (Ds). C (De) and C (Ds) are the increasing functions. Both the marginal effort cost and the marginal service cost are also the increasing functions, $C^{\prime}\left(D_{e}\right)>0, C^{\prime}\left(D_{S}\right)>0 C^{\prime \prime}\left(D_{e}\right)>0, C^{\prime \prime}\left(D_{s}\right)>0$; Equity proportion of venture capital institutions is $k$, $0 \leq \mathrm{k} \leq 1$,and the proportion of start-ups is $1-\mathrm{k}$; The rate of return to give up for venture capital institutions is $t, t>0$; The government subsidies for start-ups are $\pi, \pi \geq 0$;the private utility obtained from the wage income of the venture enterprises and the entrepreneurs is $\mathrm{u}, \mathrm{u}>0$; the tax intensity of start-ups is $\mathrm{m}$, $0 \leq \mathrm{m} \leq 1$; property and management costs that start-ups hand in incubator is $\mathrm{g}, \mathrm{g} \geq 0$; the intensity of local government return to the incubator is $h, 0 \leq h \leq 1$; the financial returns of Incubators is mainly C (De); C (Ds) is fiscal reimbursement and rental income without minus the cost of providing services. Therefore,

The expected returns of venture capital institutions are:

$$
U_{V C}=X(I) Y\left(D_{e}\right) Z\left(D_{s}\right) R\left(I, D_{e}, D_{s}\right)(1+\pi)(1-m) k-(1+t) I
$$

The expected returns of start-up entrepreneurs are:

$$
U_{E i}=X(I) Y\left(D_{e}\right) Z\left(D_{s}\right) R\left(I, D_{e}, D_{s}\right)(1+\pi)(1-m)(1-k)+u-C\left(D_{e}\right)
$$

The expected returns of business incubators are:

$$
U_{B j}=X(I) Y\left(D_{e}\right) Z\left(D_{s}\right) R\left(I, D_{e}, D_{s}\right) m h+g-C\left(D_{s}\right)
$$

\section{B. Model Analysis}

\section{1) Game equilibrium solution}

In the game process, the three-parties are independent individuals. Venture capital institutions have advantages in fund and business incubators and start-ups have advantages in information. Venture capital institutions decide whether to invest based on the credibility of the incubators, the preferential policies and the development of start-ups. Business incubators and start-ups determine the quality of service and level of effort. When the respective expected returns are maximized, the derivative of the expected reward function to the decision variables equals zero. Therefore, we can draw the behavioral function and game equilibrium solution of the three parties.

a) Behaviors of entrepreneur and business incubator

Although the efforts of start-ups and business incubator services are not determined at the same time, but in this mode, the two parties can be considered at the same time solution. Because venture capital institutions are not plunged, the startups are not formally operated yet. The efforts of start-ups can't be observed by incubators or venture capitalists, but both invested by venture capitalists (I, k) are observable. For formula (1) about De to take first-order derivative and make the derivative equal to zero. We get conditions to maximize the expected return of start-ups:

$$
\begin{aligned}
& U_{E i}^{\prime}=X(I) Z\left(D_{s}\right)(1+\pi)(1-m)(1-k)\left[Y^{\prime}\left(D_{e}\right) R+Y\left(D_{e}\right) \frac{\partial R}{\partial D_{e}}\right]-C^{\prime}\left(D_{e}\right)=0 \\
& U_{E i}^{\prime}=X(I) Z\left(D_{s}\right)(1+\pi)(1-m)(1-k)\left[Y^{\prime}\left(D_{e}\right) R+Y\left(D_{e}\right) \frac{\partial R}{\partial D_{e}}\right]=C^{\prime}\left(D_{e}\right)
\end{aligned}
$$

Formula (5) is the optimal decision of start-up, which shows that when external policy is constant, the marginal cost of effort $=$ the share of entrepreneur $\times$ the increase of final value by adding one unit of effort. Static analysis shows that start-ups are encouraged and increase their level of effort when they get more stocks and the government increase subsidies or decreases the tax revenue intensity. Venture capital institutions increase investment or incubators boost service level will also lead start-ups to improve their level of effort directly.

Similarly, we get conditions to maximize the expected return of business incubators:

$$
X(I) Y\left(D_{e}\right)\left[Z\left(D_{s}\right) \frac{\partial R}{\partial D_{S}}+Z^{\prime}\left(D_{S}\right) R\right] m h=C^{\prime}\left(D_{S}\right)
$$

Formula (6) is the optimal decision of business incubator, which means that the marginal cost of business incubator service efforts $=$ tax intensity and fiscal return intensity $\times$ the increase of final value by adding one unit of effort. Static analysis shows that when the intensity of tax revenue and fiscal return increases, it will encourage incubators to improve service quality. When venture capital institutions increase investment or entrepreneurs increase their efforts, they will also encourage incubators to improve service level. 


\section{b) Behaviors of venture investment}

Decide the proportion of shares held by the best VC firm (k)

Order: $\frac{\partial U_{V c}}{\partial p}=0$

Get: $k\left[R \frac{\partial\left(Y\left(D_{e}\right) Z\left(D_{S}\right)\right)}{\partial k}+\frac{\partial R}{\partial k} Y\left(D_{e}\right) Z\left(D_{S}\right)\right]+Y\left(D_{e}\right) Z\left(D_{S}\right) R=0$

Among that: $\frac{\partial\left(Y\left(D_{e}\right) Z\left(D_{s}\right)\right)}{\partial k}=\frac{\partial R\left(I, D_{e}, D_{s}\right)}{\partial D_{e}} \cdot \frac{\partial D_{e}}{\partial k}+\frac{\partial R\left(I, D_{e}, D_{s}\right)}{\partial D_{s}} \cdot \frac{\partial D_{s}}{\partial k}$

$$
\frac{\partial Y\left(D_{e}\right)}{\partial k}=\frac{\partial Y\left(D_{e}\right)}{\partial D_{e}} \cdot \frac{\partial D_{e}}{\partial k} \frac{\partial Z\left(D_{s}\right)}{\partial k}=\frac{\partial Z\left(D_{s}\right)}{\partial D_{s}} \cdot \frac{\partial D_{s}}{\partial k}
$$

Formula (7) shows the expected value of cash after the success of the business $=$ venture capital firm shares $\times$ the increase of final value by increasing in the proportion of shares in a unit.

\section{DECIDE ON THE OPTIMAL AMOUNT OF VENTURE CAPITAL (I)}

Order: $\frac{\partial U_{V C}}{\partial I}=0$

Get: $(1+\pi)(1+s) k\left[\frac{\partial R\left(I, D_{e}, D_{S}\right)}{\partial I} X Y Z+R \frac{\partial(X Y Z)}{\partial I}\right]=1+t$

Among that: $Y^{\prime}\left(D_{e}\right)=\frac{\partial\left(Y\left(D_{e}\right)\right)}{\partial I}=\frac{\partial\left(Y\left(D_{e}\right)\right)}{\partial D_{e}} \cdot \frac{\partial D_{e}}{\partial I}$

$$
Z^{\prime}\left(D_{S}\right)=\frac{\partial\left(Z\left(D_{S}\right)\right)}{\partial I}=\frac{\partial\left(Y\left(D_{S}\right)\right)}{\partial D_{S}} \cdot \frac{\partial D_{S}}{\partial I}
$$

Formula (8) shows that opportunity cost of the venture capital investment $=$ shares held by venture capital $\times$ net profit of marginal capital. The level of venture capital investment in start-ups will be affected by the yield return on capital markets. If the yield return on capital markets is high, the income of marginal capital will be raised accordingly.

(5) - (8) is the Nash equilibrium condition that the tripartite game maximizes respective expected returns, and will get the Nash equilibrium solution of the non-cooperative game $\left(D_{\text {enash }}(I, \pi, m, k, h), D_{\text {snash }}(I, \pi, m, k, h), k_{\text {nash }}, I_{\text {nash }}\right)$.

\section{2) Ethical risk analysis}

Ethical risk refers to those who engage in economic activities to maximize their own profits. At the same time, they make adverse actions to others. Due to information asymmetry, the three parties may create ethical risks. Venture capital institutions may not support start-ups actively. Business incubators may not provide services in place. And start-ups may also conceal their true situation or not to reflect their problems to venture capital institutions and business incubators. Moreover, business incubators and start-ups may collude to provide untruthful information to venture capital institutions and defraud more investments. This article analyzes the ethical risk in non-cooperative game.

Differentiate the expected return function of start-ups on De and Ds:

$$
\begin{aligned}
& d U_{E i}=(1+\pi)(1+m)(1-k) X(I) Z\left(D_{S}\right)\left[Y\left(D_{e}\right) R\right] d D_{e}-C\left(D_{e}\right) d D_{e} \\
& +(1+\pi)(1-m)(1-k) X(I) Y\left(D_{e}\right)\left[Z^{\prime}\left(D_{e}\right) R+Z\left(D_{e}\right) \frac{\partial R}{\partial D_{S}}\right] d D_{e} \\
& +(1+\pi)(1-m)(1-k)\left[X Y Z \frac{\partial R}{\partial Z}+\frac{\partial X Y Z}{\partial I} R\right] d I
\end{aligned}
$$

From formula (5), the first two terms on the right side of formula (9) are the optimal conditions for maximizing the revenue of startups. Zero at equilibrium and the third is positive, which indicate that business incubators have a positive externality for start-ups. So, if incubator services are in place, it will bring more reward to start-ups. The last term of formula (9) is also positive, which indicates that venture capital institutions have positive externalities for start-ups and that if the amount of investment increases, the expected value of start-ups will increase. Formula (9) shows that if business incubators improve their service level or venture capital institutions increase the investments, they will bring more revenues to start-ups. But start-ups have no incentive to change their level of effort.

Differentiate the expected return function of business incubators on De, Ds and I:

$$
\begin{aligned}
& d U_{B j}=m h X(I) Y\left(D_{e}\right)\left[Z\left(D_{s}\right) \frac{\partial R}{\partial D_{s}}+R Z^{\prime}\left(D_{s}\right)\right] d D_{s}-C^{\prime}\left(D_{s}\right) d D_{s} \\
& +m h X(I) Z\left(D_{s}\right)\left[Y^{\prime}\left(D_{e}\right) R+Z\left(D_{e}\right) \frac{\partial R}{\partial D_{e}}\right] d D_{e}+m h\left[X Y Z \frac{\partial R}{\partial I}+\frac{\partial X Y Z}{\partial I} R\right] d I
\end{aligned}
$$

From formula (5), the first two terms on the right side of formula (10) are the optimal conditions for maximizing the revenue of business incubators. Zero at equilibrium and the third is positive, which shows that start-ups have externality for business incubators. If start-ups make more efforts, it will also bring more benefits to the incubators. The last term is also positive, which indicates that venture capital institutions have externality for incubators. If the amount of investment increases, the expected value of start-ups will increase and bring more benefits to the business incubator. However, the incubator will not have any incentive to raise its own service level.

Differentiate the expected return function of venture capital institutions on De, Ds and I:

$$
\begin{aligned}
& d U_{V C}=(1+\pi)(1+m) k\left[\frac{\partial(X Y Z)}{\partial I} R+X Y Z \frac{\partial R}{\partial I}\right] d I-(1+t) d I \\
& +(1+\pi)(1+m) k X(I) Z\left(D_{S}\right)\left[Y^{\prime}\left(D_{e}\right) R+Y\left(D_{e}\right) \frac{\partial R}{\partial D_{e}}\right] d D_{e} \\
& +(1+\pi)(1+m) k X(I)_{Y}\left(D_{e}\right)\left[Z\left(D_{S}\right) \frac{\partial R}{\partial D_{S}}+R Z^{\prime}\left(D_{S}\right)\right] d D_{S}
\end{aligned}
$$

From formula (6), the first two terms on the right side of formula (11) are the optimal conditions for maximizing the revenue of venture capital institutions. Zero at equilibrium and the last two terms are positive, which manifests respectively that start-ups and business incubators have externality for venture capital institutions. If two parties raise their level of effort or quality of service, they will raise the final profits of 
the project. However, under the condition of maximum revenue, venture capital institutions have no incentive to increase the investment, and this will not make the other two parties to raise their level of effort.

\section{CONCLUSION AND SUGGESTION}

This article discusses the relationship among venture capital institutions, business incubators and start-ups from the perspective of game theory, analyzes the conditions for the tripartite game to reach Nash equilibrium, draws the game equilibrium solution and analyzes the problem of ethical risk and its causes. We conclude that there are many benefits to conduct tripartite cooperation theoretically, but it may be speculation in cooperative process due to asymmetric information.

In the interests of maximizing their own interests, the three parties have no incentive to increase their inputs, which give rise to the ultimate reward less than the optimal level. In order to solve the problem of ethical risk, this paper proposes the following countermeasures and suggestions.

\section{A. Increase government support and optimize relevant laws and regulations}

The government reduces the tax intensity and provides financial subsidies for start-ups, which can improve the enthusiasm of start-ups. The government should learn the foreign experiences and formulate laws to promote tripartite cooperation.

\section{B. Adjust the source of revenue for business incubators}

Revenue of business incubators generally consists of property revenue, service revenue and financial returns. The government should reduce the proportion of property income and increase the proportion of service income which can force business incubators to improve service quality and reduce the speculation.

\section{Establish a brand-based business incubator}

The problem of ethical risk is ultimately caused by asymmetric information. Establishing a brand-based business incubator can deepen the trust among the three parties, which can alleviate the information asymmetry and avoid generation of speculation through the brand effect.

\section{Improve the tripartite cooperation model and formulate financial contracts}

The three parties can make staged contracts. Venture capital institutions decide whether to continue investing in the next stage and how much to invest according to service status of the business incubator and the performance of the start-up, which can encourage incubators to improve service quality and make start-ups work harder. The increase of efforts and the improvement of service levels in turn attract venture capital institutions to invest more funds. That forms a virtuous circle, so that the three parties can obtain benefits as best as possible.

\section{ACKNOWLEDGMENT}

The author acknowledges the financial support from the National Social Science Foundation of China (Grant No.15ZDC022; Grant No.17BGL209) and National Natural Science Foundation of China (Grant No.71373199).

\section{REFERENCES}

[1] Liming Zhao, Shan Lu, "A Comparative Study of the Collaborative Pattern of Business Incubators and Venture Capital," SCIENCE OF SCIENCE AND MANAGEMENT OF S.\&T, 2011, Vol.32 ,pp. 131-135

[2] Yan Hu, Yun Chen, "Synergic Development Mode between Business Incubators and Risk Investments,” JOURNAL OF WUT (INFORMAT IO N \&MANAGEMENT ENGINEERING), 2004 Vol.26,pp. 166-169.

[3] Kun Zhao, Rui Sun., "The Integration Mechanisms Study of the Incubator of Scientific and Technological Enterprise and Risk Investment,"CHINASCIENCE AND TECHNOLOGY INFORMATION, 2005, Vol.16,pp. 172-173.

[4] Guangping Liu,Liwen Chen,Anbang Qi, "Research on the Investment Decision-Making and Operational Model of Technology Business Incubator," SCIENCE OF SCIENCE AND MANAGEMENT OF S. \& T, 2013, vol. 34, pp. 150-155

[5] Wenqing Wu, Haihong Zhang, Liming Zhao, "Study on Knowledge Sharing Game and Policy ofBusiness Incubator and Venture Capital," SOFT SCIENCE, 2014, Vol.28,pp. 39-43.

[6] Gangshu CAI, Ned Kock., "An evolutionary game theoretic perspective on e-collaboration:The collaboration effort and media relativeness," European Journal of Operational Research, 2008, Vol.194 (3), pp.821833

[7] Yuan Ju,Peter Borm,Pieter Ruys. "The consensus value: a new solution concept for cooperative games,” Social Choice and Welfare, 2007, Vol.28, pp.685-703. 